\title{
Eurasian Macro-Region: Choosing a Sustainable Way of Development
}

\author{
Oleg Zaporozhchenko ${ }^{1}$, Elena Radkovskaya ${ }^{2 *}$,Elena Kochkina $^{2}$, and Denis Mironov ${ }^{2}$ \\ ${ }^{1}$ GEFEN Dekel Technologies LTD, Nakhum Goldman, 41/9, 8471962 Be'er Sheva, Israel \\ ${ }^{2}$ Ural State University of Economics, 8 March Str., 62, 620144 Ekaterinburg, Russia
}

\begin{abstract}
The article substantiates the need to choose a new paradigm for the macro-regional development of Eurasia, which, along with other macro-regions, has found itself in recent decades in a situation where the old theoretical platform for regional development has ceased to correspond to modern conditions of economic and socio-political reality. The system paradigm proposed as an alternative puts forward the principle of studying the region as a holistic system based on the analysis of interconnections and relations between its individual components. This applies both to the internal relations of the system (economic, cultural, organizational, demographic, social and others), as well as interconnections with the environment external to the system. According to the authors, the growing role of economic sustainability is determined by the objective need to develop theoretical, methodological, and practical guidelines that would enable the process of transition to a sustainable development format.
\end{abstract}

\section{Introduction}

Eurasia is a unique territorial (in fact, continental) formation, which in the context of economic development can be considered as one of the largest macro-regions in the world.

In recent decades, Eurasia, along with other macro-regions, has found itself in a situation where it is necessary to choose a new development paradigm. This is due to the revealed discrepancy between the old theoretical platform of regional development and modern conditions of economic, as well as socio-political life. The global financial crisis, which led to global downturns in the economic, social and political spheres of almost all states, has become a very significant indicator of the inconsistency of the previous development policy with the current conditions. The events taking place now in Europe and America, the countries of the East and the post-Soviet space clearly prove this.

Therefore, the study of new promising ways of development and analysis of opportunities for their implementation is becoming a very urgent task for most economies at the moment.

\footnotetext{
*Corresponding author: rev@usue.ru
} 


\section{Materials and Methods}

The methodology of this study is based on the synergetic interaction of the principles of general systems theory and system analysis, in particular, the regional, space-time paradigm and the paradigm of sustainable development, as well as the concept of self-development of the region.

The instrumental and methodological apparatus includes, on the one hand, basic general scientific methods of cognition, such as comparative, typological and expert approaches, comparative analysis (static and dynamic), structural-functional and causal methods. On the other hand, a more extensive and specific study of the issues raised in the article involves the use of specialized tools of theoretical and applied research, methods of economic, mathematical and statistical modeling, factor and index analysis.

\section{Results and Discussion}

Economic policy based on the theoretical platform of neo-Keynesianism or Neoclassicism turns out to be untenable in today's reality due to the limited range of applications and inconsistency of the conditions for optimal functioning of theoretical models to the entire range of emerging economic situations.

The Keynesian movement that emerged as a reaction to the economic crisis of 19291933 , and subsequently - in the second half of the last century - actualized the reaction to changes in the situation, became a hindrance in the conditions of recovery, and vice versa, the movement of classicism that replaced it during this period - later Neoclassicism - could not properly meet the goals of national development during recessions. The provisions of both theories do not fully describe the process of expanded reproduction, focusing mainly on the search for quantitative relationships in the specific economic aspect and leaving aside the more general socio-economic goals and objectives of social development.

Today, there are many approaches to defining and studying regional aspects of development. This is due to the complex, ambiguous structure of the region itself as an object of research, and the author's preferences for certain scientific concepts. Many scientists promote a comprehensive, systematic approach to the study of regional problems, believing that it can serve as a reliable platform for analyzing the processes of regional development at the present stage, although the basic principles of the systematic approach were formulated in the 1920s and 1930s [1]. The strong point of the system paradigm is the principle of studying the region as an integral system based on the analysis of relationships between its individual components (economic, cultural, organizational, demographic, social, and other) within the system and with the external environment.

As noted by Ural scientists [2], the most important feature of the new paradigm is that it is based on understanding the essence of the regional problem generally as a multi-faceted phenomenon that covers its economic, social, environmental, cultural, spiritual, moral and other issues.

The main goal of humanity has always been and remains to improve the quality of life of modern and future generations. Moreover, the more developed a society is, the more care it tends to show for its descendants. Economic activity, first of all, the organization of effective functioning of enterprises and organizations is subjected to the same tasks and is not only their expression, but also the basic one. Currently, the world community has developed a vision of the main way to achieve this goal, which is to ensure movement towards sustainable development. Generated by the processes of globalization of the world economy, the concept of sustainable development is becoming more pronounced spatial 
character [3]. Sustainable development programs are developed and implemented at national, regional, and even municipal levels [4].

The main strategy of a sustainably developing region or macro-region, such as Eurasia is the provision of economic sustainability, since in a broad sense it is the economy that determines the conditions of development as well as production and technological, and social sectors that have the greatest impact on the environment. Although the theory of economic sustainability has not been developed completely, the work of many researchers such as P. Samuelson, J. R. Hicks, and A. Wald L. Walras - became the basis for the formation of the modern theory of economic stability. Focused mainly on the analysis of market equilibrium in conditions of perfect competition, these works, however, are quite deeply covered the issues of disproportions in the distribution of income, inconsistency of individual expectations and actual results of economic life as the causes of loss of stability, as well as the need to increase the economic functions of the state in order to maintain stability [5].

At the present stage, the main sources of the theory of economic stability are classical macroeconomic models, the general theory of organization, synergetics, the concept of sustainable development, and neoinstitutionalism. One of the most important practical conclusions for today, as it seems to us, can be considered the statement proved by A. A. Bogdanov that the stability of a system is determined to a greater extent by the stability of structural connections, rather than elements [6].

Crisis and transition stages, being an objective regularity in the development of the world economy, nevertheless, seriously aggravate the problems of the production sector, thereby undermining the economic stability of economic systems at any level - from the enterprise and industry to the national and world economy as a whole. At the same time, according to O. V. Mikhalev [5], the regional production system is particularly "experiencing" a crisis period, since the forced concentration of resources in the center of national interests leads - in the absence of effective mechanisms to counteract destabilizing factors - to a sharp drop in the economic potential of the weakened regional periphery.

The need to intensify research on economic sustainability is determined, in addition to contributing to the functioning of the economy in a crisis, also by the fact that it increases the competitiveness of the economic system, providing the advantages of a more stable system in attracting partners and investments, obtaining loans, attracting employees and employers, etc. [7].

The increasing role of economic sustainability is thus stipulated by the objective need to develop theoretical, methodological, and practical guidelines [8] that would ensure the process of the transition to a sustainable development format.

In regional terms, especially if we consider such significant territorial entities as the Eurasian macro-region, the task of achieving economic stability should first of all include the aspect of coordinating the diverse and often multidirectional interests of numerous subjects of the macro-region [9]. Ensuring equal rights in this case should apply not only to each of the citizens, as it is declared, in particular, in the report of the UN international Commission "Our common future", which outlined the principles and prospects of the concept of global sustainable development, but also - at the level under consideration - to each of the regions. At the same time, of course, it is necessary to take into account not only the own autarkic interests of each of the territories that make up the Eurasian macro-region, but also - from the point of view of economic unity - the common goals and objectives of such an Association. The basic mechanism for developing and implementing sustainable development programs should be the principle of "balance of interests".

Achieving this balance is not an easy task, especially for such a unique geographical, socio-economic and political region as Eurasia. Being the largest continent on earth, Eurasia stretches from North to South for 8 thousand $\mathrm{km}$ and from West to East - for 18 
thousand $\mathrm{km}$ and, the only one of all continents, is washed by four oceans: the Atlantic, Pacific, Indian and Arctic. The area of Eurasia is 53.6 million $\mathrm{km} 2$, and the total area of its Islands is about 3.45 million $\mathrm{km} 2$. More than 5 billion people live on the continent. Thus, Eurasia is the most densely populated continent - about $70 \%$ of the world's population lives on $36 \%$ of the earth's land area. The average population density in Eurasia is approximately 95 people per square kilometer, with an average Earth population density of about 56 people per $\mathrm{km} 2$ [10]. However, this density is distributed very unevenly - from 1000 people per km2 in the Indo-Gangetic lowlands to Mongolia - 1.97 people per km2 [11].

Eurasia is a very contrasting continent both from a socio-geographical and geopolitical point of view. Eurasia contains both the highest mountain on Earth (Chomolungma) and the lowest point on land (the Dead sea basin), the deepest lake (Baikal) and the largest sea (the Caspian sea), the largest geographical area (Siberia) and the largest Peninsula (Arabia), and even the cold pole of the Northern hemisphere (Oymyakon). The average height of the continent is $830 \mathrm{~m}$ (the highest continent on Earth), mountains and plateaus occupy about $65 \%$ of its territory [12]. All climate zones are represented on the territory of Eurasia.

However, the main difference between the Eurasian macro-region and other regions of the world is the concentration of a large number of different states on a relatively small territory. The largest number of states is located in Eurasia: depending on the accounting system (including or not self-proclaimed unrecognized and partially recognized states), Europe and Asia include from 94 to 103 states, with some countries located in both parts of the continent. For example, the European part of Russia is about $22 \%$, although the most part of the country's population lives here.

Naturally, both the level of economic development and the level of income and quality of life in different countries of Eurasia are very different from each other. At the same time, the differences relate not only to the size of economies, the predominant industry orientation and the degree of concentration of production, but also, of course, to state political interests.

Russia, as the largest state in Eurasia, plays a very significant role in ensuring the balanced development of the macro-region. Despite the fact that the implementation of its consistent policy often faces difficulties and even outspoken opposition, as exemplified by the imposed sanctions, Russia has consistently proclaimed mutual respectfor interests and mutually beneficial partnership as the main principle of interaction between all countries. The search for partners who share these positions forces Russian diplomats and entrepreneurs at this stage to pay more attention to the countries of Southeast Asia, Africa, South and Latin America. Cooperation with them both at the government level, as well as at the level of representative offices and companies, is already having a tangible effect, allowing us to realize huge potential opportunities for successful interaction in the field of business, trade, education and culture.

One of the most important tasks of the Eurasian states is to intensify the diversification of production and exports. This is especially true for the largest exporters of hydrocarbons in the region, which, in particular, include Russia, Kazakhstan, Turkmenistan, Azerbaijan, and Uzbekistan. The predominant focus on the export of raw materials (oil, gas) in the past years, despite a solid budget filling, has created many problems in the economies of these countries, and this encourages their leadership to search for new ways of development leading to greater independence and sustainability. The restoration of industrial production, the search for new areas of scientific research and financial and economic architecture have become a necessity for many post-Soviet territories and a sign of the current stage of development. At the same time, each state introduces into its structure not only basic economic elements, but also superstructure social complexes. Their forms can be different, depending on the set priorities and the specifics of life. For example, in Russia, much attention is paid to the development of social infrastructure in various areas of life support 
for the population through the implementation of national projects (medicine, insurance, demography, etc.).

Without a doubt, the issues of achieving sustainable economic and social development both in Eurasia as a whole and for individual territorial entities, implementing protectionist policies, overcoming territorial production imbalances, etc., should be resolved taking into account individual specifics, acceleration mechanisms, catalysts for economic growth and improving the state of the social sphere in each region.

\section{Conclusion}

The cardinal direction for sustainable economic development of a macro-region implies the economic sustainability of all its regions - both as relatively autonomous taxonomic units with their own unique potential, and as parts of a single economic organism that contribute to the overall development. At the same time, when determining the policy of long-term development of each region, taking into account its most powerful aspects, it is necessary to remember that in socio-economic terms, sustainable development of the macro-region is possible only if the situation of all regions is sufficiently balanced.

However, for the countries of the Eurasian macro-region, as well as for all other states, it is impossible to achieve truly sustainable development only by solving internal problems. At the current stage of development, no country can develop in isolation, and achieving global goals, such as preserving civilization, protecting the natural environment, and ensuring decent living conditions for present and future generations, is a big common task that can only be achieved through the joint efforts of all states.

\section{References}

1. E. A. Utkin, A. F. Denisov, State and municipal government (2001)

2. From the idea of Lomonosov to the real development of the territories of the Urals, Siberia and the Far East (2009)

3. I. V. Naumov, Economics of the region, 15 (2019)

4. The formation of the skeleton of economic security in the aspect of ensuring sustainable development of the region (2017)

5. O. V. Mikhalev, Economic sustainability of regional economic systems: author. diss. ... doctor. econ. sciences (2011)

6. A. A. Bogdanov, Tectology. General organizational science (2003)

7. E. V. Radkovskaya, G. V. Radkovskiy, Fundamental research, 10 (2019)

8. A. V. Kotov, Economics of the region, 16/2 (2020)

9. E. B. Dvoryadkina, E. A. Belousova, Manager, 11/3 (2020)

10. Earth population counter, https://countrymeters.info/

11. GEO, https://geo.koltyrin.ru/

12. Geography. Modern illustrated encyclopedia (2006) 